RUNNING HEAD: CHILD MALTREATMENT, ADOLESCENT ATTACHMENT STYLE, AND DATING VIOLENCE

Child maltreatment, adolescent attachment style, and dating violence: Considerations in youths with borderline-to-mild intellectual disability

Jonathan A. Weiss, Jennifer, MacMullin, Randall Waechter, Christine Wekerle, The MAP Research Team 


\begin{abstract}
One of the most salient developmental tasks of adolescence is the entry into romantic relationship, which often involves developing attachments to partners. Adolescents with a history of maltreatment have been found to be at greater risk of insecure attachments to romantic partners than non-maltreated adolescents, and the interaction of maltreatment and insecure attachment style has been linked to dating violence. The current study examined attachment styles and dating violence in child welfare-involved adolescents with borderline-to-mild intellectual disability $(n=40)$ and with average IQ $(n=116)$. Despite reporting similar experiences of childhood maltreatment, IQ was found to interact with avoidant attachment style to predict the degree of dating violence victimization and perpetration experienced by youth. It is suggested that an avoidant attachment style is a risk factor for all maltreated youth, and holds a particularly strong effect on youth with lower IQ levels. These findings highlight the need for developmentally appropriate attachment and dating violence interventions for maltreated youth.
\end{abstract}

Keywords: Maltreatment, Intellectual Disability, Dating Violence, Attachment, Adolescence 


\section{Child maltreatment, adolescent attachment style, and dating violence: Considerations in youths with borderline-to-mild intellectual disability}

One of the most salient developmental tasks of adolescence is the entry into romantic relationships; developing and consolidating personal and interpersonal skills (e.g., Connolly \& McIsaac, 2009). With adolescence viewed as an extended time frame, from ages 15 to 30 years at their outside parameters (Arnett, 2001), regardless of the individual youth characteristics and circumstances, most youth will have been in at least one "serious" or attachment relationship (Carver et al., 2003). An attachment relationship would be distinguished from a transient one by virtue of the partner being a salient emotional partner. This includes a preference for proximity to the person (by frequent or regular contact and communication), as well as feelings of safety and connectedness as a secure base to return to in distress and uncertainty (Fraley and Shaver, 2000; Hazen and Shaver, 1987). While normatively emotional and physical safety would be foundational functions of attachment, for those raised in relational contexts of violence, this may not be a primary goal. Primary goals may relate more to survival advantage in terms of obtaining and sustaining provisions, maintaining affiliations, and having a regular, known sexual partner. The socio-emotional and cognitive relationships worldview is captured by an attachment theory (Bowlby, 1982) approach to adolescent and adult relationship style (Allen and Land, 1999; Bartholomew and Horowitz, 1991; Crittenden and Claussen, 2002; Hazen and Shaver, 1987). Maltreatment can cause an individual to approach interactions with a tendency to look for aggressive cues, foster interpretations of others' behavior to indicate threat, and develop pre-emptive protective, and potentially violent, responses (Bugental, 1993; Rieder and Cicchetti, 1989). Thus, romantic relationships 
may mimic features of victimization, including aggressive modes of relating, difficulties establishing personal limits, impaired initiation or negotiation of physical and emotional intimacy experiences, as well as failures in self-protection (e.g., Auslander et al., 2002; DiLillo, 2001; O’Leary et al., 1994; Ornduff et al., 2001; Wall and McKee, 2002; Wekerle and Avgoustis, 2003). For example, dating violence as a perpetration (e.g., Wolfe et al., 2004) or victimization (Wekerle, et al., 2009) seems to reflect, in part, emergency emotions like distress, feelings of threat and overwhelming stress, as well as anger, perhaps as a response to vulnerability. Styles of relating, or attachment styles (e.g., Grych and Kinsfogel, 2010; Wekerle and Wolfe, 1998), provide one theoretical window within which to understand dating relationships in maltreated youth with impaired intellectual functioning.

One sub-population of adolescents where knowledge about relationships and sexuality is severely limited is youths with intellectual disability (ID) (Cuskelly and Bryde, 2004; Isler et al., 2009). Intellectual disability refers to significant limitations in intellectual functioning (as measured by IQ) and adaptive behavior (conceptual, social or practical skills) that are present before 18 years of age (Schalock et al., 2007). Prevalence rates for mild ID (IQ score of 55-69, between 2 and 3 standard deviations below the IQ mean) are estimated at .5-1\% of the population (Leonard and Wen, 2002), and rates of borderline ID (IQ score of 70-84, between 1 and 2 standard deviations below the IQ mean) are substantially higher, estimated at approximately $12 \%$ (Emerson et al., 2010).

Within the population of maltreated youth involved in the child protective services system (CPS), those with borderline-to-mild ID are a particularly critical group to consider, especially in terms of risk for negative outcomes, such as poor mental health 
or dating violence (e.g., Vig and Kaminer, 2002; Weiss et al., in press). In general, CPS involved youth are a unique population to consider maltreatment-related impairment (e.g., Jonson-Reid et al., 2007; McMillen et al., 2005). In particular, youth with less frank (i.e. detectable) levels of intellectual impairment are significantly under-studied, especially those with borderline levels of intellectual functioning (Emerson et al., 2010). Youth with borderline-to-mild degrees of ID may be even more susceptible to maltreatment compared to children with more severe disabilities (Jaudes and Shapiro, 1999). Parents of children with a mild disability may not understand the limitations associated with disability, and misattribute undesirable behavior to the youth's character rather than to the disability (Vig and Kaminer, 2002). Youth with ID are exposed to more psychosocial risk factors and social disadvantage compared to typically developing peers, as well as prolonged stigmatization, and repeated social and academic failures (Emerson and Hatton, 2007; Mansell et al., 1998). Research with adult women with ID has pointed to a high risk for intimate partner violence (Carlson, 1998; McCarthy, 1999; Ward et al., 2010).

Intimate partner violence is defined as "any behavior within an intimate relationship that causes physical, psychological, or sexual harm", including acts of physical aggression, psychological abuse, sexual coercion, and controlling behaviors" (Heise and Garcia-Moreno, 2002, p. 89). Rates of intimate partner violence are very high in the general population of youth: Up to $35 \%$ of typically developing youth have experienced insults, threats, and intimidation (Carver et al., 2003), approximately $9.8 \%$ of students in the US have been hit, slapped or physically hurt on purpose by their boyfriend or girlfriend during the previous 12 months, and $7.4 \%$ of youth have been physically 
forced to have sexual intercourse when they did not want to (Centres for Disease Control and Prevention, 2010). Similar rates of dating aggression (reporting at least one act of aggression with a current or past partner) were found for 16-year-old boys and girls from Canada (33\%) and Italy (34\%) (Connolly et al., 2010a, b). Recent research regarding the high rates of dating violence in university students across 16 countries (in Asia, Middle East, Australia-New Zealand, Europe, Latin America, and North America) highlights the global nature of dating violence (Straus, 2004).

For individuals with ID, dating violence in the form of sexual assault is a widespread concern (Lumley et al., 1998). Between $68 \%$ and $83 \%$ of women with ID will experience sexual abuse in their lifetime. However, less than $50 \%$ will seek professional support (Guidry, 2001). Individuals with ID may be especially vulnerable to sexual assault because of impairments in judgment, social skills, and communication (Sobsey, 1988). Individuals with ID are more likely to rely on others for care (Guralnick, 1999) and are less likely to seek help or report abuse than individuals of average IQ (Lang and Frenzel, 1988). Some authors have suggested that this increased risk is related to a lack of knowledge about appropriate sexual behavior or of skills to defend themselves against abuse (Lang and Frenzel, 1988), or to being more likely to comply with abusive requests (Sobsey and Varnhagen, 1988). Little is known regarding dating violence in individuals with ID that is not sexual in nature. More generally, women with disabilities are more likely than those without a disability to report being hit, slapped, pushed, kicked, or physically hurt by a dating partner (30.6\% vs. 15.7 ; Armour et al., 2008). In a recent study of 47 adolescents and adults with ID, $60 \%$ of those who had been in romantic 
relationships reported such interpersonal violence, with no gender differences noted (Ward et al., 2010).

Maltreatment, attachment processes, and dating violence: The context of intellectual disability

It has been argued that adolescent relationship violence stems from an interaction between maladaptive attachment processes and maltreatment (Alexander, 2009; Doumas et al., 2008; Grych and Kinsfogel, 2010; Sims et al., 2008; Straus and Savage, 2005; Vezina and Hebert, 2007; Wekerle et al., 2009; Wolfe et al., 2009; Wolfe et al., 2004). Attachment theory proposes that children develop internal working models of themselves in relationships, and others as relationship partners, based on experiences with caregivers (Bowlby, 1969, 1982). Attachment theory has been extended to understand adolescent and adult romantic relationships as conscious manifestations of the attachment process, namely a typical style of relating or attachment style. This coherence across relationship history has received support: for example, adolescents' reported attachment quality to caregivers has been correlated with the quality of their (dating) relationships and the expectations they hold of marriage, with insecure attachment in adolescents related to negative (but not necessarily violent) dating experiences (Steinberg et al., 2006). Using the Adult Attachment Interview, Furman (2001) found that attachment styles are also related to working models of friendships.

Each attachment style is thought to reflect different beliefs about romantic relationships, the availability and trustworthiness of a romantic partner, and the worthiness of the individual to be loved. Attachment styles are often conceptualized as continuous features relating to three aspects (i.e., secure, avoidant, and 
anxious/ambivalent relationship styles; Collins and Sroufe, 1999; Fraley and Shaver, 2000; Hazan and Shaver, 1987; 1994). According to Shaver and Hazan (1993), securely attached individuals are interested in close romantic relationships and are capable of forming long-term relationships; avoidant individuals are uncomfortable with close, longterm relationships; and anxious/ambivalent individuals are keen to engage romantically with others but are focussed on potential rejection and abandonment. In a community sample of adolescents, a history of self-reported maltreatment has been found to interact with avoidant and ambivalent attachment styles to predict males' perpetration of abuse toward their romantic female partner, while the level of secure attachment was found to interact with maltreatment history to reduce the likelihood of female-to-male selfreported perpetration (Wekerle and Wolfe, 1998). Further, maltreatment history interacted with anxious-ambivalent attachment style to predict males' reported victimization at the hands of their female partners (Wekerle and Wolfe, 1998). More recently, in a sample of 391 adolescents aged 14-18 years, Grych and Kinsfogel (2010) demonstrated that romantic attachment moderates the relationship between family aggression and dating aggression. In other words, romantic attachment has an influence on the way in which family aggression impacts behavior in dating relationships.

There is growing evidence to suggest that youth with ID are less likely to be classified as securely attached compared to typically developing peers and peers with other types of disabilities, although most work to date has focused on infants and children. Two meta-analyses have emerged to suggest that children with neurological conditions that are often associated with ID (e.g., Down syndrome, autism) show more insecure attachment compared to children without intellectual disabilities (Clements and 
Barnett, 2002; van IJzendorn et al., 1992; van IJzendorn et al., 1999). Even in children with severe developmental delays, such as pervasive developmental disorder, the presence of an ID is often associated with greater insecure attachment (WillemsenSwinkels et al., 2000).

Howe (2006a) proposed a transactional model of child and parent vulnerability factors to explain why youth with disabilities are more likely to be maltreated and have insecure attachments. Parents who care for children with ID often experience increased levels of stress compared to parents of typically developing individuals, which may decrease parental engagement (i.e., sensitivity, perceived competence, and emotional persistence), perhaps activating parents' own unresolved attachment problems. Less sensitive and responsive parenting would then interact with children's communication to produce less synchronicity and greater anxiety and fear in interactions, leading to insecure attachment patterns (Atkinson et al., 1999). At the same time, the heightened level of need and vulnerability inherent in having a disability can increase the risk of punitive, discipline-based or helpless and neglectful parenting, which would foster a subsequent insecure attachment style. There is preliminary research to suggest that early attachment relationships in people with ID, even those with severe ID, can influence subsequent relationship trajectories in adulthood. For example, reactive attachment disorder symptoms in adults with ID, characterized by severely inappropriate social relating to caregivers and peers as a result of pathogenic care have been correlated with a history of childhood adversity and maltreatment (Minnis et al., 2010). Because of their increased level of dependency across the lifespan, adults with severe ID who live in residential settings (i.e., group homes) are likely to develop attachment relationships with 
their paid caregivers, and insecurely attached persons are more likely to demonstrate challenging behaviors with their caregivers in times of stress (Clegg and LansdallWelfare, 1995; Janssen et al., 2002).

Research is needed to examine risk and protective processes that impact the risk for dating violence in people with ID, particularly when a history of maltreatment is known. The goal of this study was to examine the interaction between intellectual functioning and attachment style in predicting romantic relationship violence in maltreated youth who are involved with CPS agencies. It is critical to investigate the issues that likely affect maltreated adolescents with borderline-to-mild ID, such as dating violence, in order to support their developmental transition into young adulthood. Based on previous research with non-ID youth, it was hypothesized that: a) maltreated youth with borderline-to-mild ID would have higher rates of dating violence than maltreated youth with average IQ; b) maltreated youth with ID would have higher insecurity scores than maltreated youth with average IQ; and c) attachment styles would function as a moderator of the relationship between maltreatment and dating violence for youth with and without ID. No specific predictions about the type of insecure attachment style are warranted given the limited work with youths with ID.

\section{Method}

This paper used data from the Maltreatment and Adolescent Pathways (MAP) Longitudinal Study of Child Protection Services (CPS)-involved youth. MAP participant scores on the Kaufman Brief Intelligence Test (KBIT) were used to select the majority group (average IQ) and a contrast group (borderline-to-mild ID). The MAP study follows teens, aged 14.0 to 17.0 , over two years, testing them every 6 months to a three-year 
follow-up. The KBIT was administered at the MAP one-year follow-up mark. Testers were mainly child clinical psychology students who were trained and supervised by Ph.D.-level psychologists.

Potential MAP youth were selected from a random numbers table from CPS agency-provided master lists of all active cases aged 14.0 to 17.0 within an urban catchment area, with information restricted to youth basic demographics and caseworker name (for further details on MAP study methodology, see Waechter et al., 2009; Wekerle et al., 2009). After CPS agency staff liaison checked the case status, the CPS liaison connected with appropriate caseworkers, who then made a judgment on exclusion criteria. Reasons for ineligibility included crisis-level mental health and residential issues, as well as a severe developmental disorder and disability that would impair the youth's ability to independently complete about $2 \mathrm{~h}$ of assessment that consisted mostly of commercially-available and standardized questionnaires. At this point, $56 \%$ of CPSinvolved youth were found to be ineligible, mainly due to the case file being opened for a very short period of time (i.e., less than six months). Developmental delay (12\%) and interfering mental health issues $(9 \%)$ were the next highest reasons for ineligibility. Caseworkers obtained consent for MAP research staff to call the youth and provide more information. The recruitment rate of eligible youth at the initial testing point is just under $70 \%$, with refusals mainly due to youth stating that they were "too busy" to participate. The rate of parents refusing consent for youth under age 16 years, and youth in Temporary Care ${ }^{1}$ was relatively low $(5 \%)$. The caseworker was the consent provider for

\footnotetext{
${ }^{1}$ CPS-involved youth were classified as either a: (1) Crown Ward through an order of the court, wherein the CPS agency is the legal guardian, (2) Society Ward, which refers to youth who are placed in the care of CPS by a court order for a period of less than 12 months, (3) Temporary Care Ward, which refers to a youth who may be the subject of a temporary order of care and custody, or in care through a temporary care
} 
Crown and Society Ward youths. All youths over 16 years of age provided their own consent to participate.

In comparing demographic differences between MAP study participants versus non-participants, no significant differences were found in age, gender or type of maltreatment. More participating youth came from longer-term, in care placements, and fewer youth resided with their birth families, $\chi^{2}(1, N=560)=112.02, p<.001$. Pilot testing determined the upper limit of testing time and all youth were paid to minimum wage for this time per MAP testing point. Youth were paid $\$ 28.00$, given refreshments, and reimbursed for any travel. Most youth $(80 \%)$, though, elected to be tested in their place of residence.

\section{Participants: Current Report}

In this paper, we report on a subset of MAP youth $(N=254)$ with completed intelligence testing. ${ }^{2}$ Of this group, $14 \%(n=35)$ had Verbal IQ - Performance IQ discrepancies that were noted as significantly large and clinically important ( 24 points or greater; Kaufman and Kaufman, 1990), and were removed from analyses. A further 19 youth received a severe Childhood Trauma Questionnaire (CTQ) Minimization-Denial score of 3 , and were removed from the sample. ${ }^{3}$ Finally, to ensure that all the youth in the current sample experienced clinically significant levels of maltreatment, only youth who met with at least one cut-off score greater than in the "mild" range on the CTQ were included; another 33 were removed from the sample, leaving 167 youth. To compare

agreement, or (4) Community Family, which reflects situations where the CPS agency becomes involved to help a family while the youth remains in the family.

2 This population was also examined in Weiss et al. (in press).

${ }^{3}$ The CTQ Minimization-Denial Scale point is given if a participant notes 'very often' to any the following items: 'There is nothing I wanted to change about my family', 'I had the perfect childhood', and 'I had the best family in the world'. 
youth with borderline-to-mild ID to those with average intellectual functioning, youth with IQ composite scores between 60 - 84 were identified as being in the borderline-tomild ID group $(n=40)$, with $30 \%$ of those youth having scores between $60-70$, in the range of mild ID. Youth with IQ scores between 85 and 115 were placed in the average IQ group $(n=116)$.

As shown in Table 1, the average age at MAP entry was 15.8 years $(S D=1.01$; 42\% male), which included diverse ethnicity (youth-identified ethnicity: 29\% White, $24 \%$ Black, $31 \%$ reporting being two or more ethnicities). Most youth in this subset were Crown Wards (78\%). Youth in the borderline-to-mild ID group reported having fewer computers in their homes than youth in the average IQ group, $t(146)=-2.40, p=.02$. There were no significant group differences in age, gender, CPS involvement, type of residence, or other socioeconomic indicators. Youth in both groups noted having begun dating at approximately 13 years of age $(S D=2.35)$. Groups did not differ in the age at which they first began having intercourse, $t(110)=.42, p=.68$ or in the number of serious relationships that they noted having, $t(120)=.47, p=.64$. In addition, the length of the longest relationship in grades $9,10,11$, and 12 was not significantly different between the two groups (all $p>.05$ ). Youth in the borderline-to-mild ID group were more likely to have dated someone who was younger in age than youth with average IQ, $t(75)=2.98, p<.01$. Youth with average IQ were less likely to fight about money $(19 \%$ vs. $\left.34 \%, \chi^{2}(1, N=156)=4.19, p=.05\right)$, and about seeing other people $\left(33 \%\right.$ vs. $50 \%, \chi^{2}$ $(1, N=156)=365, p=.06)$ compared to youth with borderline-to-mild ID. The borderline-to-mild IQ group had significantly lower composite, verbal, and performance IQ standard scores than youth in the Average IQ group (all $p<.001$ ). 


\section{Measures}

The following measures administered as part of the MAP study protocol were analyzed for this report.

\section{1) IQ: Kaufman Brief Intelligence Test (KBIT)}

The norm-referenced KBIT was given as a brief screening measure of IQ (Kaufman and Kaufman, 1990). The KBIT has been shown to have adequate to excellent reliability $($ split-half $=.74-.97$, test-retest $=.80-97)$ and construct validity $(r=.58-.80)$ (Kaufman and Kaufman, 1990).

2) Maltreatment: Childhood Trauma Questionnaire (CTQ)

Experiences of childhood maltreatment were assessed by the self-report Childhood Trauma Questionnaire (CTQ; Bernstein et. al., 1994). The CTQ uses a standard stem (e.g., "While you were growing up..."), rating 28 items on a 5-point scale $(1=$ never true to $5=$ very often true) across five subscales: emotional neglect, physical neglect, sexual abuse, physical abuse, and emotional abuse. Three of the 28 questions are validity items and there are five items per subscale. Two-week test-retest reliability of the CTQ for a MAP youth sub-sample $(n=52)$ was moderate across subscales (ranging from .52 to .70), while internal validity was good (ranging from .68 to .92). Youth and worker's rating of childhood maltreatment are significantly correlated in terms of physical abuse, sexual abuse, and physical neglect $(r=.26-.58)$, but not emotional abuse or neglect. 
3) Dating Violence: Conflict in Adolescent Dating Relationships Inventory (Wolfe et al., 2001).

The CADRI is an 80 -item self-report measure that assesses overt and covert forms of violence, intimidation, and positive communication both expressed and experienced by youth in their (minimum of 2 weeks) dating relationships. Youth rate the frequency of various conflict resolution strategies over the past 12 months on a four-point scale $(0=$ never, $1=$ rarely, $2=$ sometimes, $3=$ often). A dating relationship is defined as not single dates and of 2 weeks or longer. As used previously (Wekerle et al., 2001), a short form was derived from seven pairs of perpetration-victimization items that had the highest loading on factors generated from an exploratory factor analysis of CADRI items. These items (victimization version) are: (1) I said things just to make my partner angry, (2) I kicked, hit, or punched my partner, (3) I slapped or pulled my partner's hair,

(4) I threatened to hurt my partner, (5) I threatened to hit or throw something at my partner, (6) I pushed, shoved, shook, or pinned down my partner, and (7) I threatened my partner in an attempt to have sex. The seven perpetration items are tallied up to form a perpetration score and the seven victimization items are tallied up to for a victimization score. Two week test-retest reliability of the MAP subsample was moderate $(r=.38$ for perpetration and $r=.44$ for victimization), while internal validity was high $\left(\alpha_{\iota}=.85\right.$ for perpetration and $\alpha_{\llcorner}=.91$ for victimization).

\section{4) Attachment style: Attachment Security Ratings}

The attachment security ratings, based on Hazan and Shaver's work $(1987,1994)$, consist of relationship descriptions that parallel the three main types of attachment style (secure, anxious/ambivalent, avoidant), and have been used successfully to measure 
attachment style in adolescents (Wekerle and Wolfe, 1998). Respondents rate their position on a scale ranging from $1=$ not at all like me to $7=$ very like me (Shaver and Brennan, 1992). For example, the anxious/ambivalent description is as follows: "I find that others are reluctant to get as close as I would like. I often worry that my partner doesn't really love me or won't want to stay with me. I want to merge completely with another person and this desire sometimes scares people away." According to the attachment ratings, attachment style is conceptualized as current relationship expectations. Examining attachment styles on a continuous domain, where adolescents hold levels of secure, avoidant, and ambivalent tendencies towards their romantic partners, is important to avoid misclassifying or losing individuals who rate themselves highly on more than one attachment style (Kirkpatrick and Davis, 1994).

\section{Data analysis plan}

First, group differences on study variables of interest are examined between ID and non-ID youths (maltreatment; attachment style; dating violence). Second, to assess the moderating influence of attachment style on IQ in predicting violence in relationships, hierarchical regression analyses were used (Baron and Kenny, 1986). Separate hierarchical regressions were calculated, entering control variables first, followed by ID group second, attachment style rating third, and the product of ID grouping and attachment style last. Control variables included gender, a proxy measure of socioeconomic status (number of computers in the home), CAS Status (Crown Ward vs. not), and youth age. Separate regressions were calculated for each attachment style (secure, avoidant, and anxious/ambivalent). Data were examined for multicollinearity, homoscedasticity and extreme outliers prior to analysis. 


\section{Results}

\section{1) Experience of maltreatment}

Based on the CTQ clinical cut-off scores, $73 \%$ of the youth reported a history of at least moderate levels of one form of maltreatment or another. This includes $60 \%$ of youth who reported physical abuse at any level (including 35\% at the severe level), 27\% who reported sexual abuse (including $22 \%$ at the moderate or severe levels), $68 \%$ who reported emotional abuse (including $31 \%$ at the severe level), $83 \%$ who reported emotional neglect (including 30\% at the severe level), and $66 \%$ who reported physical neglect (including 28\% at the severe level). As was expected from a CPS-involved population, the vast majority of these youths (87\%) reported experiencing at least mild levels of more than one form of abuse, based on any CTQ clinical cut-off levels.

Rates and severity of maltreatment were similar across adolescents with borderline-to-mild ID and those with average IQ. Chi-square tests of independence confirmed that borderline-to-mild ID and average IQ youth did not differ in the proportion of each group experiencing clinically significant levels of maltreatment based on the CTQ clinical cutoff levels on emotional abuse, $\chi^{2}(3, N=156)=2.17, p=.54$, sexual abuse, $\chi^{2}(3, N=191)=3.95, p=.27$, physical abuse, $\chi^{2}(3, N=156)=2.84, p=$ .42 , or physical neglect, $\chi^{2}(3, N=156)=2.56, p=.47$. A greater proportion of youth with borderline-to-mild ID reported severe levels of emotional neglect (50\%) compared to average IQ youth $(23 \%), \chi^{2}(3, N=156)=10.93, p=.02$. A CTQ total abuse composite score was calculated by summing cases that met the CTQ clinical cut-off at the moderate-severe levels. A two-way Gender X IQ ANOVA revealed no significant main 
effects for IQ, $F(1,152)=.09, p=.77$, gender, $F(1,156)=.74, p=.39$, and no interaction, $F(1,152)=.91, p=.34$.

2) Perpetrating and victimization of dating violence

Adolescents with borderline-to-mild ID reported significantly more victimization and perpetration of relationship violence. A two-way (Gender X IQ Group) ANOVA on overall mean CADRI victimization scores revealed a trend for an interaction, $F(1,102)=$ $3.07, p=.08$, and a significant main effect of IQ, $F(1,102)=6.67, \mathrm{p}=.01$, but no gender main effect, $F(1,102)=1.32, p=.25$. Overall, youth with average IQ reported significantly less dating violence victimization than youth with borderline-to-mild ID. A similar two-way ANOVA examining overall mean perpetration of dating violence revealed a trend for a main effect of IQ, $F(1,102)=3.71, p=.06$, no significant main effect for gender, $F(1,102)=.55, p=.46$, and no interaction effect, $F(1,102)=.86, p=$ .36. Youth with borderline-to-mild ID reported more perpetration than individuals with average IQ. There was a strong correlation between overall victimization and perpetration across groups, $r(107)=.76, p<001$.

Table 2 presents the percentages of youth in each group who report on perpetration and victimization in the past year. Chi-square tests of independence revealed that a greater percentage of youth with borderline-to-mild ID threatened to hit their partner or throw something at their partner compared to average IQ youth, $\chi^{2}(1, N=108)$ $=7.53, p=.006$, had a partner that pushed, shoved, or shook them, $\chi^{2}(1, N=108)=8.08$, $p=.004$, and that threatened them in an attempt for sex, $\chi^{2}(1, N=103)=5.83, p=.04$ (Fisher's Exact Test).

3) Attachment style 
There were few differences in attachment styles between groups, although one clear gender X IQ interaction did emerge. A two-way (Gender X IQ Group) ANOVA on secure attachment revealed a nonsignificant effect of gender, $F(1,148)=3.01, p=.09$, of IQ, $F(1,145)=.1 .11, p=.30$, or an interaction between the two, $F(1,145)=1.39, p=$ .24. A similar two-way ANOVA examining avoidant attachment revealed a significant gender X IQ interaction, $F(1,145)=6.12, p=.02$, but no significant main effect for gender, $F(1,145)=2.79, p=.10$, or for IQ, $F(1,145)=.74, p=.39$. Post hoc contrasts demonstrated that females with average IQ reported higher levels of avoidant attachment than males with average IQ, $F(1,145)=18.87, p<.001$, a difference not observed between males and females with borderline-to-mild ID, $F(1,145)=.21, p=.65$. Males with borderline-to-mild ID reported higher levels of avoidant attachment compared to males with average IQ, $F(1,145)=4.27, p=.04$, while there was no difference between females with borderline-to-mild ID and average IQ, $F(1,145)=1.86, p=.18$. A third two-way ANOVA, examining differences in levels of anxious/ambivalent attachment, revealed no main effect for gender, $F(1,145)=.09, p=.77$, IQ, $F(1,145)=.004, p=.95$, or interaction between the two, $F(1,145)=3.00, p=.09$.

4) Examining attachment style as a moderator for IQ

Table 3 presents the intercorrelations among attachment style ratings and mean CADRI victimization and perpetration scores. There was a small negative correlation between secure attachment and victimization, $r(104)=-.20, p=.04$. There were also small positive correlations between avoidant attachment and victimization, $r(102)=.33$, $p=.001$, and perpetration, $r(102)=.30, p=.002$. Although moderator analyses call for no correlation among moderator and outcome (Baron and Kenny, 1986), the small effect 
sizes found here would be expected given the shared focus on relationships (Wekerle and Wolfe, 1998).

The first set of hierarchical regressions was calculated to examine the moderating influence of attachment styles on IQ in predicting relationship violence victimization. As shown in Table 4, none of the control variables emerged as significant predictors of relationship victimization at the initial step as a whole or individually at the final model, for secure, avoidant, or anxious attachment style. Secure attachment style and anxious attachment style failed to emerge as significant predictors or moderators of IQ in understanding domestic violence victimization. Avoidant attachment was found to be a significant predictor of victimization when it was entered into the model on the third step, although the inclusion of the interaction between IQ and avoidant attachment level led to the loss of this significant direct relation among avoidant attachment style and victimization. IQ grouping (Dummy variable $0=$ average IQ, $1=$ borderline-to-mild ID), also emerged as a significant predictor in the final model, when avoidant attachment was the examined attachment style $(B=.18, t=-1.97, p=.05)$. To assess the IQ $\mathrm{X}$ avoidant attachment interaction, the predicted standardized scores based on the overall model were calculated, and plotted with avoidant attachment level on the $\mathrm{X}$ axis and level of predicted victimization on the $\mathrm{Y}$ axis. As shown in Figure 1, greater levels of avoidant attachment have a stronger influence on youth with borderline-to-mild ID than on youth with average IQ. The risk of experiencing dating violence increased for all youth as they began to show more avoidant attachment, but to a much greater degree for youth with borderline-to-mild ID. 
A second set of hierarchical regressions was calculated examining perpetration of domestic violence as the outcome. As shown in Table 5, the control variables as a group accounted for a small but significant amount of variance in violence perpetration, although none of the specific control variables emerged as unique predictors in the overall model. The only clear factor that emerged as a significant predictor of relationship violence perpetration was the interaction of IQ and avoidant attachment. As shown in Figure 2, the same pattern of interaction emerged as in the case of dating violence victimization.

\section{Discussion}

From an ecological systems perspective, multiple risk factors across different contexts influence the prevalence of dating violence for adolescents (e.g., Connolly et al., 2010). Experiencing maltreatment is one of the strongest predictors of violence victimization and perpetrations in dating relationships (Malik et al., 1997; Wekerle and Wolfe, 1998). Results from the current sample of maltreated adolescents in CPS confirm high rates of relationship violence. For instance, maltreated youth are more likely to have an early entry to dating (Wekerle et al., 2009) and intercourse (Taussig, 2002) than nonmaltreated youth. Based on results from the 2005 Canadian Community Health Survey, $29 \%$ of adolescents aged 15 to 17 years and $65 \%$ of adolescents aged 18 to 19 years have had intercourse (Rotermann, 2008). However, of the 877 youth (aged 11-14 years) involved in the child welfare system who completed the National Survey of Child and Adolescent Well-Being (NSCAW), 50.4\% reported having consensual sexual intercourse (40.5\% of whom were 13 years of age or younger at the time of first consensual intercourse) (James et al., 2009). In the current sample, youth began dating on average at 
13 years of age $(S D=2.35)$, and began having intercourse at 13.7 years of age $(S D=$ 1.79). Unfortunately, a normative developmental experience can be a context for revictimization. Yet, partnership can also be a means of resilience (Scott et al., 2005). It is critical to understand the social support pathway that includes romantic relationships.

The present results revealed, as expected by our first hypothesis, that adolescents with borderline-to-mild ID reported more victimization and perpetration of relationship violence, compared to adolescents with average IQ. Maltreated individuals with borderline-to-mild ID are likely at risk of dating violence as a result of increased presence of risk factors related to poor outcomes than youth without ID (Emerson and Hatton, 2007). Adolescents with borderline-to-mild ID likely have access to fewer resources for developing healthy relationships (McCabe, 1999) and, therefore, may be more susceptible to perpetuating a cycle of violence.

Our second hypothesis was only partially supported. For the most part, youth with ID did not differ in levels of insecure attachment from youth without ID. Given the robust impact that a history of maltreatment has on attachment style (Baer and Martinez, 2006; Howe, 2006b; Morton and Browne, 1998; Reyome, 2010), and the lack of a significant difference in reported maltreatment history between groups (with both groups experiencing high levels of maltreatment), it is not surprising that we found similar levels of secure and avoidant/ambivalent attachment styles. Males with borderline-to-mild ID did report higher levels of avoidant attachment compared to males with average IQ, but also compared to females with and without ID. Typically developing adolescent males have been shown to have higher rates of avoidant attachment to maternal caregivers than adolescent females (Doyle and Markiewicz, 2009), and the present results suggest that of 
males, those with impaired intellectual functioning may be particularly prone to such insecure style.

Our analysis also revealed a significant positive correlation among avoidant attachment style and perpetration and victimization of violence across groups. This finding replicates the results from Wekerle and Wolfe (1998), who surveyed 321 high school students and identified avoidant attachment style as a predictor of relationship violence for females. Supporting the third hypothesis, avoidant attachment style in the current study was found to moderate the relationship between IQ and violence victimization and perpetration, after controlling for gender, SES, age, and CPS Status. Our regression analyses demonstrated that, in maltreated adolescents, the positive relation between avoidant attachment style and relationship violence is much stronger for youth with borderline-to-mild ID. Attachment representation appears to play an important role in relationship violence, especially among individuals with borderline-to-mild ID.

In light of this association between attachment styles and cognitive ability, it is worth noting that intellectual functioning is emerging as an important variable in understanding outcomes for youth who experience maltreatment. This is only the second study to examine psychosocial outcomes for maltreated youth with intellectual impairments who are involved in CPS. In a recent study of 165 maltreated adolescents involved in CPS, Weiss et al. (in press) found that intellectual functioning as well as emotional abuse at the hands of a caregiver (including witnessing caregiver domestic violence) emerged as a significant predictor of psychological distress. Specifically, after controlling for levels of emotional maltreatment, adolescents with borderline-to-mild ID 
reported significantly higher levels of psychological distress compared to adolescents with average IQ.

\section{Attachment-based Interventions}

The results reported here point to the need for developmentally appropriate attachment-based interventions. With children, many attachment-focused interventions are focused on rectifying the relationship between parent and child. Child-Parent Psychotherapy (CPP) is one such type of attachment-based therapy that has shown to be effective for treating young children who have experienced family violence (Busch and Lieberman, 2007). Emphasis is placed on the relationship between child and caregiver, with the aim of transitioning insecurely attached relationships to secure ones. The goals of CPP are threefold: increase reciprocity in the parent-child relationship, improve emotion regulation in the child and the parent, and address posttraumatic stress symptoms (Busch and Lieberman, 2007). After receiving CPP, mothers show higher levels of empathy and interactiveness with their children and children demonstrate an increase in attachment security and less disorganized behavior (Lieberman et al., 1991; Toth et al., 2002). Unfortunately, existing attachment-based interventions tend to focus on very young children (Bakermans-Kranenburg et al., 2003; Cohen et al., 1999), and there is continued need for interventions to address the needs of older children and adolescents. Muller $(2009 ; 2010)$ provides an introduction to specific interventions for adults who have experienced intrafamilial trauma and have developed an avoidant attachment style, which can be extended developmentally to adolescents. He recommends addressing the identity of the victim, using symptoms as motivators, and listening for, noticing, and 
using ambivalence. These strategies are intended to activate the attachment system and challenge defensive avoidance in the client-therapist relationship.

To our knowledge, attachment-based interventions have yet to be implemented in children or adolescents with borderline-to-mild ID. There is some preliminary evidence for its use with children and youth with severe ID and multiple impairments. Sterkenburg et al. (2008) investigated the effect of attachment-based therapy and behavior modification for six children with visual impairments and severe ID. Children had severe behavioral challenges such as self-injury, aggression and disruption, and a history of pathogenic care. Participants received attachment-based behaviour therapy alternating with a control treatment in which a different therapist positively engaged with the client. The intervention consisted of the Attachment-based Behavior Modification Treatment, which was divided into three phases: developing attachment with the therapist through sensitive responding, replacing maladaptive behavior with socially appropriate behavior, and generalizing the clients' socially appropriate behavior. Across the six participants, the attachment-based therapy was associated with increased adaptive behavior compared to the control therapy. A similar attachment-based intervention has been recently implemented in a case series of adolescents with severe ID and visual impairment (Schuengel et al., 2009), showing that attachment-based behaviour modification was more effective than behaviour modification alone.

\section{Interventions for Dating Violence in Adolescents}

Interventions that address dating violence are also important. One intervention that has addressed dating violence in maltreated adolescents is the Youth Relationship Project (YRP; Wolfe et al., 2006), a community based manualized intervention that 
consists of 18 sessions aimed at promoting healthy dating relationships and preventing cycles of violence. The curriculum focuses on education and awareness of abuse and power dynamics in close relationships, skill development, and social action. Wolfe et al. (2003) examined the effectiveness of the program with 158 adolescents (14-16 years of age) with a history of maltreatment who were actively involved in CPS. Decreases in the frequency and severity of dating violence victimization and perpetration were seen in both the intervention and control group; however, adolescents participating in the intervention group decreased at a faster rate. Although attachment change was not measured as part of the study, dating violence involvement and trauma symptoms declined for adolescents involved in the intervention program.

Another program that addresses dating violence among adolescents is The Safe Dates Program, which aims to provide primary and secondary prevention of dating violence to adolescents (Foshee et al., 2000). The intervention consists of both school and community activities, including a theatre production performed by adolescents and educational sessions provided by health and physical education teachers (Foshee et al., 1996). Baseline data were obtained from 1,886 adolescents enrolled in $8^{\text {th }}$ and $9^{\text {th }}$ grade. One month post intervention, reductions were seen in psychological, physical and sexual abuse perpetration among males and females (Foshee et al., 1998). After 1 year, there were no significant differences in abuse perpetration or victimization between the control group and the intervention group; however, adolescents in the perpetrators subsample who received the intervention reported using less destructive responses to anger and were more aware of perpetrator services compared to the control group. Combined, these interventions show that it is possible to curtail relationship violence among adolescents 
with focused interventions. A critical next step is to examine how content and delivery might be effectively modified to the cognitive needs of adolescents with borderline-tomild intellectual impairments.

Due to the private and sensitive nature of the material under investigation, this study relied on self-report measures of behavior. Although it is important to be aware of the possibility of response bias, self-report methods have been shown to provide reliable and valid indications of behavior (Bernstein et al., 1994). Another limitation of the current study is that we are unable to determine causality because data collection was cross sectional in nature. The relationships between attachment, IQ, and dating violence that are reported in this study are correlational. The relatively small sample size of this clinical sample also limits the power of statistical analyses, decreasing the likelihood of possible weaker relationship emerging. Finally, the sample of individuals with ID included in the MAP study are not representative of all individuals with ID in CPS, as they were required to have a minimal skill level required to complete self-report measures without caregiver report and did not have formal diagnoses of ID. While this appears to be a limitation, it may be the case that given selection criteria, the MAP study includes the highest-functioning child welfare-involved youth with ID. If this is the case, the significant relationship between avoidant attachment and dating violence perpetration/victimization reported here, which is greater for youth with ID, may be even more powerful among lower-functioning CPS youth. Further research is necessary to examine this possibility.

Prevalence rates of maltreatment of children with disability have long been known, yet data regarding the experience and outcomes of adolescents with ID who have 
been maltreated is only now emerging. Research is needed to examine the risk and protective factors that moderate the course for these youth, in order to target biopsychosocial factors to promote resilience. Failing to study this subgroup of children in CPS can result in a failure to recognize their unique needs, placing this marginalized and at-risk sub-population of youth at further risk and disadvantage. 
Table 1. Descriptive statistics

\begin{tabular}{|c|c|c|c|}
\hline Variables & $\begin{array}{c}\text { Total sample } \\
\quad N=153 \\
M(\mathrm{SD})\end{array}$ & $\begin{array}{l}\text { Borderline- } \\
\text { Mild IQ } \\
N=40 \\
M(\mathrm{SD})\end{array}$ & $\begin{array}{c}\text { Average IQ } \\
N=114 \\
M(\mathrm{SD})\end{array}$ \\
\hline Age in years & $15.8(.98)$ & $15.9(.98)$ & $15.8(1.01)$ \\
\hline Gender (\% Male) & 42 & 35 & 42 \\
\hline Age at first dating & $12.9(2.20)$ & $13.1(2.06)$ & $12.7(2.37)$ \\
\hline Age at first sexual intercourse & $13.7(1.95)$ & $13.8(1.66)$ & $13.7(1.79)$ \\
\hline KBIT Composite score $* * *$ & $90.6(14.12)$ & $73.5(6.57)$ & $97.6(7.36)$ \\
\hline KBIT Matrices score $* * *$ & $93.3(15.27)$ & $74.8(8.15)$ & $100.8(7.62)$ \\
\hline KBIT Vocabulary score $* * *$ & $89.8(12.60)$ & $77.1(8.56)$ & $95.0(8.82)$ \\
\hline $\begin{array}{l}\text { Ethnicity: } \\
\text { - White } \\
\text { - Black } \\
\text { - Other } \\
\text { - Combination of two or more }\end{array}$ & $\begin{array}{l}29.4 \% \\
23.5 \% \\
16.4 \% \\
30.7 \%\end{array}$ & $\begin{array}{c}35 \% \\
30 \% \\
7.5 \% \\
27.5 \%\end{array}$ & $\begin{array}{l}27.4 \% \\
21.2 \% \\
19.5 \% \\
31.9 \%\end{array}$ \\
\hline $\begin{array}{l}\text { CPS Status: } \\
\text { - Crown Ward (parent rights legally } \\
\text { terminated) } \\
\text { - Society Ward (parent-CPS sharing rights) } \\
\text { - Temporary Care } \\
\text { - Community Family/ Voluntary Care }\end{array}$ & $\begin{array}{l}67 \% \\
13 \% \\
2.6 \% \\
16 \%\end{array}$ & $\begin{array}{l}10 \% \\
2.5 \% \\
20 \%\end{array}$ & $\begin{array}{c}68.1 \% \\
\\
14.7 \% \\
2.6 \% \\
14.7 \%\end{array}$ \\
\hline $\begin{array}{l}\text { Socioeconomic status: } \\
\text { - \# computers at home * } \\
\text { - \# cars in home } \\
\text { - In the place you lived most of your life, } \\
\text { caregivers own or rent? (\% Owned) }\end{array}$ & $\begin{array}{c}2.4(.68) \\
2.1(.78) \\
45 \%\end{array}$ & $\begin{array}{c}2.3(.70) \\
2.1(.84) \\
40 \%\end{array}$ & $\begin{array}{c}2.6(.67) \\
2.3(.73) \\
60 \%\end{array}$ \\
\hline $\begin{array}{l}\text { What did you argue about? } \\
\text {-Friends } \\
\text {-Entertainment } \\
\text {-Sex } \\
\text {-Money* } \\
\text {-Seeing other people* } \\
\text {-Someone's parents or relatives } \\
\text {-Personal appearance } \\
\text {-Being "out" about sexual orientation } \\
\text {-Schoolwork } \\
\text {-Drugs or alcohol } \\
\text {-Keeping promises } \\
\text {-Other conflicts }\end{array}$ & $\begin{array}{c}57 \% \\
23 \% \\
31 \% \\
24 \% \\
38 \% \\
27 \% \\
12 \% \\
7 \% \\
21 \% \\
34 \% \\
34 \% \\
48 \%\end{array}$ & $\begin{array}{c}61 \% \\
22 \% \\
39 \% \\
34 \% \\
49 \% \\
25 \% \\
9 \% \\
10 \% \\
20 \% \\
31 \% \\
31 \% \\
46 \%\end{array}$ & $\begin{array}{c}54 \% \\
23 \% \\
27 \% \\
19 \% \\
33 \% \\
28 \% \\
14 \% \\
5 \% \\
21 \% \\
35 \% \\
35 \% \\
48 \%\end{array}$ \\
\hline
\end{tabular}

$$
{ }^{*} p<.05 .{ }^{* *} p<.01 .{ }^{* * *} \mathrm{p}<.001
$$


Table 2. Rates of perpetration and victimization by dating violence (at least one occurrence) during the last year by IQ group (CADRI)

\begin{tabular}{lllllll}
\hline Item & $\begin{array}{l}\text { Perpetration } \\
\text { Borderline- } \\
\text { Mild ID } \\
\%\end{array}$ & $\begin{array}{l}\text { Average } \\
\text { IQ }\end{array}$ & $\mathrm{p}$ & $\begin{array}{l}\text { Victimization } \\
\text { Borderline- } \\
\text { Mild IQ } \\
\text { Average }\end{array}$ & $\begin{array}{l}\text { ID } \\
\%\end{array}$ \\
& 50 & 50 & 1.00 & 54 & 50 & .75 \\
$\begin{array}{l}\text { Said things just to make } \\
\text { partner angry }\end{array}$ & 20 & 12 & .28 & 24 & 10 & .08 \\
$\begin{array}{l}\text { Kicked, hit or punched } \\
\text { partner }\end{array}$ & 16 & 7 & .20 & 16 & 11 & .52 \\
$\begin{array}{l}\text { Slapped partner or pulled } \\
\text { partners hair }\end{array}$ & 16 & 6 & .12 & 12 & 9 & .62 \\
$\begin{array}{l}\text { Threatened to hurt partner } \\
\begin{array}{l}\text { Threatened to hit partner or } \\
\text { throw something at partner }\end{array}\end{array}$ & 28 & 7 & .006 & 12 & 6 & .34 \\
$\begin{array}{l}\text { Pushed, shoved, or shook } \\
\text { partner }\end{array}$ & 21 & 12 & .30 & 29 & 7 & .004 \\
$\begin{array}{l}\text { Threatened partner in an } \\
\text { attempt to have sex with } \\
\text { partner }\end{array}$ & 0 & 0 & - & 12 & 1 & .02 \\
\hline
\end{tabular}


Table 3. Correlations between victimization, perpetration and the attachment security ratings

\begin{tabular}{|c|c|c|c|c|}
\hline & 1. & 2. & 3. & 4. \\
\hline $\begin{array}{l}\text { 1. I find it } \\
\text { relatively easy to } \\
\text { get close to } \\
\text { others... }\end{array}$ & & & & \\
\hline $\begin{array}{l}\text { 2. I am somewhat } \\
\text { uncomfortable } \\
\text { being close to } \\
\text { others.... }\end{array}$ & $-.36 * *$ & & & \\
\hline $\begin{array}{l}\text { 3. I find that } \\
\text { others are } \\
\text { reluctant to get as } \\
\text { close as I would } \\
\text { like... }\end{array}$ & .07 & .15 & & \\
\hline 4. Victimization & $-.20 *$ & $.33 * *$ & -.07 & \\
\hline 5. Perpetration & -.16 & $.30 * *$ & -.04 & $.76^{* *}$ \\
\hline
\end{tabular}


Table 4. Hierarchical multiple regression analyses examining predictors of dating violence victimization

\begin{tabular}{lllll}
\hline Independent variables & $R^{2}$ & $R^{2}$ Change & $\begin{array}{l}F \text { for } R^{2} \\
\text { Change }\end{array}$ & $B$ \\
\hline 1. Control variables & .03 & .03 & .66 & \\
1a. Gender & & & & .01 \\
1b. CAS Status & & & & .05 \\
1c. Age & & & & .05 \\
1d. Personal computer & .05 & .03 & 2.64 &. .09 \\
2. IQ & .09 & .03 & 3.51 & -.12 \\
3. Secure attachment & .11 & .02 & 1.82 & -.34 \\
4. IQ * Secure attachment & .03 & .03 & .66 & .03 \\
1. Control variables & & & & .04 \\
1a. Gender & & & & .03 \\
1b. CAS Status & & & & -.06 \\
1c. Age & .05 & .03 & 2.64 & $-.35^{*}$ \\
1d. Personal computer & .16 & .11 & $12.19^{* * *}$ & .15 \\
2. IQ & .25 & .09 & $11.21^{* * *}$ & $.63^{* *}$ \\
3. Avoidant attachment & .03 & .03 & .66 & \\
4. IQ * Avoidant attachment & & & & -.02 \\
1. Control variables & & & & .02 \\
1a. Gender & & & & .07 \\
1b. CAS Status & & & & -.11 \\
1c. Age & .05 & .03 & 2.64 & .21 \\
1d. Personal computer & .06 & $<.01$ & .37 & -.04 \\
2. IQ & .06 & $<.01$ & .10 & -.06 \\
3. Anxious attachment & & & \\
4. IQ * Anxious attachment & & & & \\
\hline
\end{tabular}

Note: $\mathrm{B}=$ standardized regression coefficient for final equation.

$* \mathrm{p} \leq .05, * * \mathrm{p} \leq .01, * * * \mathrm{p} \leq .001$ 
Table 5. Hierarchical multiple regression analyses examining predictors of dating violence perpetration

\begin{tabular}{lllll}
\hline Independent variables & $R^{2}$ & $R^{2}$ Change & $\begin{array}{l}F \text { for } R^{2} \\
\text { Change }\end{array}$ & $B$ \\
\hline 1. Control variables & .09 & .09 & $2.43^{*}$ & \\
1a. Gender & & & & -.16 \\
1b. CAS Status & & & & .03 \\
1c. Age & & & & .02 \\
1d. Personal computer & .11 & .02 & 2.29 & .18 \\
2. IQ & .12 & $<.01$ & .90 & -.11 \\
3. Secure attachment & .12 & $<.01$ & .09 & .07 \\
4. IQ * Secure attachment & .09 & .09 & $2.43^{*}$ & \\
1. Control variables & & & & -.16 \\
1a. Gender & & & & .04 \\
1b. CAS Status & & & & -.01 \\
1c. Age & .11 & .02 & 2.29 & -.15 \\
1d. Personal computer & .17 & .05 & $5.92^{*}$ & .09 \\
2. IQ & .22 & .05 & $6.27^{* *}$ & $.48^{*}$ \\
3. Avoidant attachment & .09 & .09 & $2.43^{*}$ & \\
4. IQ * Avoidant attachment & & & & -.18 \\
1. Control variables & & & & .03 \\
1a. Gender & & & & .03 \\
1b. CAS Status & & & & -.19 \\
1c. Age & .11 & .02 & 2.29 & .25 \\
1d. Personal computer & .12 & $<.01$ & .14 & .01 \\
2. IQ & .12 & $<.01$ & .53 & -.14 \\
3. Anxious attachment & & & \\
4. IQ * Anxious attachment & & & & \\
\hline
\end{tabular}

Note: $\mathrm{B}=$ standardized regression coefficient for final equation.

$* \mathrm{p} \leq .05, * * \mathrm{p} \leq .01, * * * \mathrm{p} \leq .001$ 
Figure 1. IQ X Avoidant attachment style interaction in relation to CADRI dating violence victimization

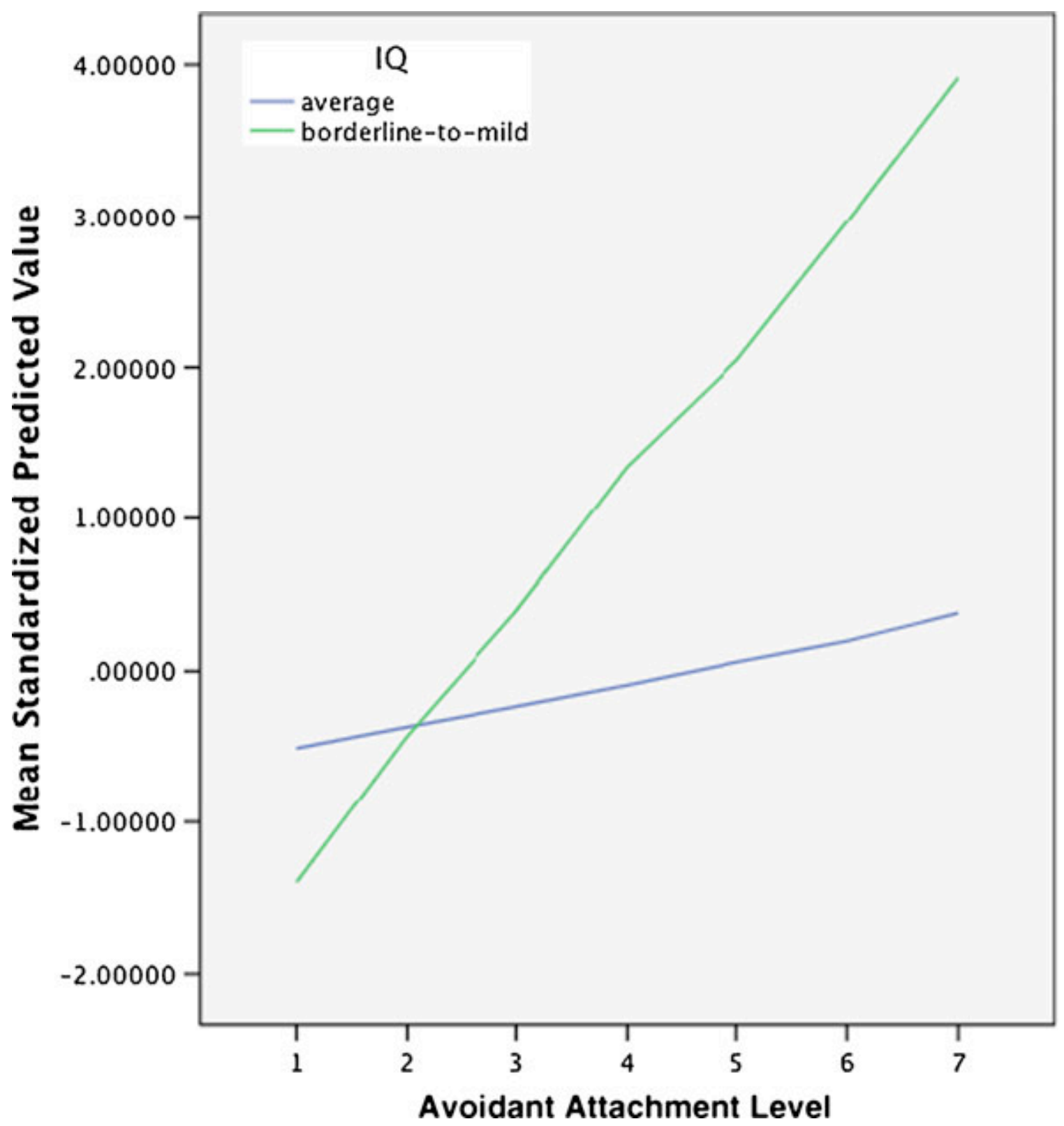


Figure 2. IQ X Avoidant attachment style interaction in relation to CADRI dating violence perpetration

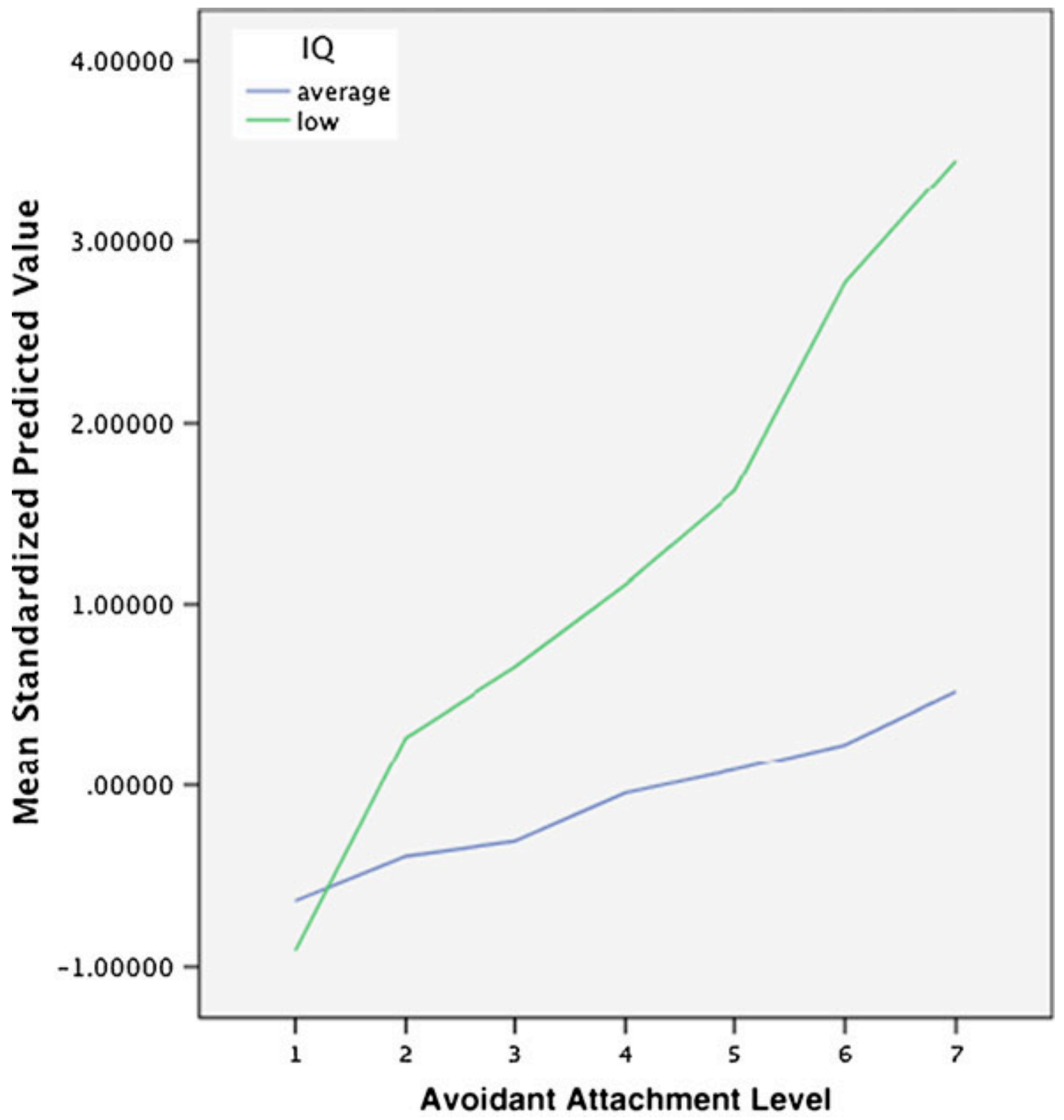




\section{References}

Alexander, P. C. (2009). Childhood trauma, attachment, and abuse by multiple partners. Psychological Trauma: Theory, 1(1), 78-88.

Allen, J. P., \& Land, D. (1999). Attachment in adolescence. In J. Cassidy \& P. R. Shaver (Eds.), Handbook of attachment: Theory, research, and clinical applications (pp. 319-335). New York: Guilford Press.

Armour, B. S., Wolf, L. A., Mitra, M., \& Brieding, M. (2008, October). Differences in intimate partner violence among women with and without a disability. Paper presented at the American Public Health Association conference, San Diego, CA.

Arnett, J. J. (2001). Conceptions of the transition to adulthood: Perspectives from adolescence through midlife. Journal of Adult Development, 8(2), 133-143.

Atkinson, L., Chisholm, V. C., Scott, B., Goldberg, S., Vaughn, B. E., Blackwell, J., Dickens, S., et al. (1999). Maternal sensitivity, child functional level, and attachment in Down syndrome. Monographs of the Society for Research in Child Development. 64(3), 45-66.

Auslander, W. F., McMillen, J. C., Elze, D., Thompson, R., Jonson-Reid, M., \& Stiffman, A. (2002). Mental health problems and sexual abuse among adolescents in foster care: Relationship to HIV risk behaviors and intentions. AIDS and Behavior, 6(4), 351-359.

Baer, J. C., \& Martinez, C. D. (2006). Child maltreatment and insecure attachment: A meta-analysis. Journal of Reproductive and Infant Psychology, 24(3), 187-197. 
Bakermans-Kranenburg, M. J., Van Ijzendoorn, M. H., \& Juffer, F. (2003). Less is more: meta-analyses of sensitivity and attachment interventions in early childhood. Psychological Bulletin, 129(2), 195-215.

Baron, R. M., \& Kenny, D. A. (1986). Moderator-mediator variable distinction in social psychology research: Conceptual, strategic, and statistical considerations. Journal of Personality and Social Psychology, 51(6), 1173-1182.

Bartholomew, K., \& Horowitz, L. M. (1991). Attachment styles among young adults. Journal of Personality and Social Psychology, 61, 226-244.

Bernstein, D. P., Fink, L., Handelsman, L. Foote, J., Lovejoy, M., Wenzel, K., et al. (1994). Initial reliability and validity of a new retrospective measure of child abuse and neglect. American Journal of Psychiatry, 151, 1132-1136.

Bowlby, J. (1969). Attachment and loss. Vol. 1. Attachment. London: Hogarth.

Bowlby, J. (1982). Attachment and loss: Retrospect and prospect. American Journal of Orthopsychiatry, 52(4), 664-678.

Bugental, D. B. (1993). Communication in abusive relationships: Cognitive constructions of interpersonal power. American Behavioral Scientist, 36(3), 288-308.

Busch, A. L., \& Lieberman, A.F. (2007). Attachment and trauma: An integrated approach to treating young children exposed to family violence. In D. Oppenheim \& D. F. Goldsmith (Eds.), Attachment Theory in Clinical Work with Children (pp. 139171). New York: The Guilford Press.

Carlson, B. E. (1998). Domestic violence in adults with mental retardation: Reports from victims and key informants. Mental Health Aspects of Developmental Disabilities, $1,102-112$. 
Carver, K., Joyner, K., \& Udry, J. R. (2003). National estimates of adolescent romantic relationships. In P. Florsheim (Ed.), Adolescent romantic relations and sexual behavior: Theory, research, and practical implications (pp. 23-56). Mahwah, NJ: Erlbaum.

Centres for Disease Control and Prevention. Youth Risk Behavior Surveillance-United States, 2009. Surveillance Summaries. MMWR 2010, 59 (No. SS-5)

Clegg, J. A., \& Lansdall-Welfare, R. (1995). Attachment and learning disability: A theoretical review informing three clinical interventions. Journal of Intellectual Disability Research, 39(4), 295-305.

Clements, M., \& Barnett, D. (2002). Parenting and attachment among toddlers with congenital anomalies: Examining the Strange Situation and attachment Q-sort. Infant Mental Health Journal, 23(6), 625-642. doi:10.1002/imhj.10040

Cohen, N. J., Muir, E., Parker, C. J., Brown, M. Lojkasek, M., Muir, R., \& Barwick, M. (1999). Watch, wait, and wonder: Testing the effectiveness of a new approach to mother-infant psychotherapy. Infant Mental Health Journal, 20, 429-451.

Collins, W. A., \& Sroufe, L. A. (1999). Capacity for intimate relationships: A developmental construction. In W. Furman, B. B. Brown, \& C. Feiring (Eds.), The development of romantic relationships in adolescence. Cambridge studies in social and emotional development (pp. 125-147). New York: Cambridge University Press.

Connolly, J., Friedlander, L., Pepler, D., Craig, W., Laporte, L. (2010). The ecology of adolescent dating aggression: Attitudes, relationships, media use, and sociodemographic risk factors. Journal of Aggression, Maltreatment \& Trauma, 19, 
469-491.

Connolly, J., \& McIsaac, C. (2009). Romantic relationships in adolescence. In R. M. Lerner \& L. Steinberg (Eds.), Handbook of adolescent psychology, Vol 2: Contextual influences on adolescent development ( $3^{\text {rd }}$ ed.) (pp. 105-151). Hoboken, NJ: John Wiley \& Sons Inc

Connolly, J., Nocentini, A., Menesini, E., Pepler, D., Craig, W., \& Williams, T. S. (2010). Adolescent dating aggression in Canada and Italy: A cross-national comparison. International Journal of Behavioral Development, 34(2), 98-105.

Crittenden P. M., \& Claussen, A. H. (2002). Developmental psychopathology perspectives on substance abuse and relationship violence. In C. Wekerle \& A. Wall (Eds.), The violence and addiction equation: Theoretical and clinical issues in substance abuse and relationship violence (pp. 123-149). New York, NY: Brunner-Routledge.

Cuskelly, M., \& Bryde, R. (2004). Attitudes towards the sexuality of adults with an intellectual disability: parents, support staff, and a community sample. Journal of Intellectual and Developmental Disability, 29(3), 255-264.

doi:10.1080/13668250412331285136

DiLillo, D. (2001). Interpersonal functioning among women reporting a history of childhood sexual abuse: Empirical findings and methodological issues. Clinical Psychology Review, 21(4), 553-576.

Doumas, D. M., Pearson, C. L., Elgin, J. E., \& McKinley, L. L. (2008). Adult attachment as a risk factor for intimate partner violence. Journal of Interpersonal Violence, 23(5), 616 . 
Doyle, A. B., \& Markiewicz, D. (2009). Attachment style with father and mother in early adolescence: Gender differences and perceived peer competence. European Journal of Developmental Scienc, 3(1), 80-93.

Emerson, E., Einfeld, S., \& Stancliffe, R. J. (2010). The mental health of young children with intellectual disabilities or borderline intellectual functioning. Social Psychiatry and Psychiatric Epidemiology, 45(5), 579-587.

Emerson, E., \& Hatton, C. (2007). Mental health of children and adolescents with intellectual disabilities in Britain. British Journal of Psychiatry, 191(6), 493-499.

Foshee, V. A., Bauman, K. E., Arriaga, X. B., Helms, R. W., Koch, G.G., \& Linder, G. F. (1998). An evaluation of Safe Dates an adolescent dating violence prevention program. American Journal of Public Health, 88(1), 45-50.

Foshee, V. A., Bauman, K. E., Greene, W. F., Koch, G. G., Linder, G. F., \& MacDaugall, J. E. (2000). The safe dates program: 1 year follow-up results. American Journal of Public Health, 90(10), 1619-1622.

Foshee, V., Linder, G.F., Bauman, K.E., Langwick, S.A., Arriaga, X. B. et al. (1996). The safe dates project: theoretical basis, evaluation design, and selected baseline findinds. American Journal of Preventive Medicine, 12, 39-47.

Fraley, R. C., \& Shaver, P. R. (2000). Adult romantic attachment: Theoretical developments, emerging controversies, and unanswered questions. Review of General Psychology. Special Issue: Adult Attachment, 4(2), 132-154. 
Furman, W. (2001). Working models of friendships. Journal of Social and Personal Relationships, 18(5), 583-602.

Grych, J. H., \& Kinsfogel, K. M. (2010). Exploring the role of attachment style in the relation between family aggression and abuse in adolescent dating relationships. Journal of Aggression, 19(19), 624-640.

Guidry Tyiska C. (2001). Working with victims of crime with disabilities. Washington, DC: Office for Victims of Crime, Department of Justice.

Guralnick, M. J. (1999a). Family and child influences on the peer-related social competence of young children with developmental delays. Mental Retardation and Developmental Disabilities Research Reviews, 5(1), 21-29.

Hazan, C., \& Shaver, P. (1987). Romantic love conceptualized as an attachment process. Journal of Personality and Social Psychology, 52(3), 511-524. doi:10.1037/00223514.52 .3 .511

Hazan, C., \& Shaver, P. (1994). Attachment as an organizational framework for research on close relationships. Psychological Inquiry, 5(1), 1-22. doi:10.1207/s15327965pli0501_1

Heise, L., \& Garcia-Moreno, C. (2002). Violence by intimate partners. In Krug E.G et al., (Eds.), World report on violence and health (pp. 87-121). Geneva: World Health Organization.

Howe, D. (2006a). Disabled children, parent-child interaction and attachment. Child and Family Social Work, 11, 95-106.

Howe, D. (2006b). Disabled children, maltreatment, and attachment. British Journal of Social Work, 36, 743-760. 
Isler, A., Beytut, D., Tas, F., \& Conk, Z. (2009). A study on sexuality with the patterns of adolescents with intellectual disability. Sexuality and Disability, 27(4), 229-237.

James, S., Montgomery, S. B., Leslie, L. K., \& Zhang, J. (2009). Sexual risk behaviors among youth in the child welfare system. Children and Youth Services Review, 31(9), 990-1000.

Janssen, C. G. C., Schuengel, C., \& Stolk, J. (2002). Understanding challenging behaviour in people with severe and profound intellectual disability: A stressattachment model. Journal of Intellectual Disability Research, 46(6), 445-453.

Jaudes, P. K., \& Shapiro, L. D. (1999). Child abuse and developmental disabilities. In J. A. Silver, B. J. Amster, \& T. Haecker (Eds.), Young children and foster care: A guide for professionals (pp. 213-234). Baltimore: Paul Brookes.

Jonson-Reid, M., Scott, L. J., McMillen, J. C., \& Edmond, T. (2007). Dating violence among emancipating foster youth. Child and Youth Services Review, 29(5), 557571.

Kaufman, A. \& Kaufman, N. (1990). Kaufman Brief Intelligence Test. Circle Pines, MN: American Guidance Service.

Kirkpatrick, L. A., \& Davis, K. E. (1994). Attachment style, gender, and relationship stability: A longitudinal analysis. Journal of Personality and Social Psychology, $66(3), 502-512$.

Lang, R. A., \& Frenzel, R. R. (1988). How sex offenders lure children. Annals of Sex Research, 1(2), 303-317. 
Leonard, H., \& Wen, X. (2002). The epidemiology of mental retardation: challenges and opportunities in the new millennium. Mental Retardation and Developmental Disabilities Research Reviews, 8(3), 117-134.

Lieberman, A. F., Weston, D. R., \& Pawl, J. H. (1991). Preventive intervention and outcome with anxiously attached dyads. Child Development, 62, 199-209.

Lumley, V. A., Miltenberger, R. G., Long, E. S., Rapp, J. T., \& Roberts, J. A. (1998). Evaluation of a sexual abuse prevention program for adults with mental retardation. Journal of Applied Behavior Analysis, 31(1), 91-101. doi:10.1901/jaba.1998.31-91

Malik, S., Sorenson, S. B., \& Aneshensel, C. S. (1997). Community and dating violence among adolescents: Perpetration and victimization. Journal of Adolescent Health, 21(5), 291-302. doi:10.1016/S1054-139X(97)00143-2

Mansell, S., Sobsey, D., \& Moskal, R. (1998). Clinical findings among sexually abused children with and without developmental disabilities. Mental Retardation, 36(1), $12-22$.

McCabe, M. P. (1999). Sexual knowledge, experience and feelings among people with disability. Sexuality and Disability, 17(2), 157-170.

McCarthy, M. (1999). Sexuality and women with learning disabilities. London: Jessica Kingsley Publishers.

McMillen, J. C., Zimba, B. T., Scott Jr, L. D., Auslander, W. F., Munson, M. R., Ollie, M. T., \& Spitznagel, E. L. (2005). Prevalence of psychiatric disorders among older youths in the foster care system. Journal of the American Academy of Child \& Adolescent Psychiatry, 44(1), 88-95. doi:10.1097/01.chi.0000145806.24274.d2 
Minnis, H., Fleming, G., \& Cooper, S. (2010). Reactive attachment disorder symptoms in adults with intellectual disabilities. Journal of Applied Research in Intellectual Disabilities, 23, 398-403.

Morton, N., \& Browne, K. D. (1998). Theory and observation of attachment and its relation to child maltreatment: a review. Child Abuse \& Neglect, 22(11), 10931104. doi:10.1016/S0145-2134(98)00088-X

Muller, R.T. (2009). Trauma and dismissing (avoidant) attachment: Intervention strategies in individual psychotherapy. Psychotherapy Theory, Research, Practice, Training, 46, 68-81.

Muller, R. T. (2010). Trauma and the Avoidant Client: Attachment-Based Strategies for Healing. New York: WW Norton \& Co Inc.

O'Leary, K., Malone, J., \& Tyree, A. (1994). Physical aggression in early marriage: Prerelationship and relationship effects. Journal of Consulting and Clinical Psychology, 62(3), 594-602.

Ornduff, S. R., Kelsey, R. M., \& O'Leary, K. D. (2001). Childhood physical abuse, personality, and adult relationship violence: A model of vulnerability to victimization. American Journal of Orthopsychiatry, 71(3), 322-331.

Reyome, N. D. (2010). The effect of childhood emotional maltreatment on the emerging attachment system and later intimate relationships. Journal of Aggression, Maltreatment \& Trauma, 19(1), 1-4.

Rieder, C., \& Cicchetti, D. (1989). Organizational perspective on cognitive control functioning and cognitive-affective balance in maltreated children. Developmental Psychology, 25(3), 382-393. 
Rotermann, M. (2005). Sex condoms and STDs among young people. Health Reports, $16(3), 39-45$.

Schalock, R. L., Luckasson, R. A., \& Shogren, K. A., Borthwick-Duffy, S., Bradley, V., Buntinx, W. H. E., et al. (2007). The renaming of mental retardation: Understanding the change to the term intellectual disability. Intellectual and Developmental Disabilities, 45(2), 116-124.

Schuengel, C., Sterkenburg, P. S., Jeczynski, P., Janssen, C. G. C., \& Jongbloed, G. (2009). Supporting affect regulation in children with multiple disabilities during psychotherapy: A multiple case design study of therapeutic attachment. Journal of Consulting and clinical Psychology, 77(2), 291.

Scott, J., Stewart, L., \& Wolfe, D. (2005). Dating relationships among at-risk adolescents: An opportunity for resilience? In R. D. Peters, B. Leadbeater, \& R. J. McMahon (Eds.). Resilience in children, families, and communities: Linking context to practice and policy (pp. 83-100). New York: Kluwer Academic/Plenum Publishers.

Shaver, P. R., \& Brennan, K. A. (1992). Attachment styles and the "Big Five" personality traits: Their connections with each other and with romantic relationship outcomes. Personality and Social Psychology Bulletin, 18, 536-545.

Shaver, P. R., \& Hazan, C. (1993). Adult romantic attachment: Theory and evidence. In D. Perlman \& W. Jones (Eds.), Advances in personal relationships (pp. 29-70). London: Jessica Kingsley. 
Sims, E. N., Dodd, V. J., \& Tejeda, M. J. (2008). The relationship between severity of violence in the home and dating violence. Journal of Forensic Nursing, 4(4), $166-173$.

Sobsey, D. (1988). Sexual offenses and disabled victims: Research and practical implications. Visà-Vis: A National Newsletter on Family Violence, 6(4).

Sobsey, D., \& Varnhagen, C. (1988). Sexual Abuse and Exploitation of People with Disabilities. Final Report. Retrieved from http://www.eric.ed.gov/ERICWebPortal/contentdelivery/servlet/ERICServlet?acc no $=\mathrm{ED} 346620$

Steinberg, S. J., Davila, J., \& Fincham, F. (2006) Adolescent marital expectations and romantic experiences: Associations with perceptions about parental conflict and adolescent attachment security. Journal of Youth and Adolescence, 35, 333-348.

Sterkenburg, P. S., Janssen, C. G. C., \& Schuengel, C. (2008). The effect of an attachment-based therapy for children with visual and severe intellectual disabilities. Journal of Applied Research in Intellectual Disabilities, 21, 126-135.

Sterkenburg, P., Schuengel, C., \& Janssen, C. (2008). Developing a therapeutic relationship with a blind client with a severe intellectual disability and persistent challenging behaviour. Disability \& Rehabilitation, 30(17), 1318-1327.

Straus, M. A. (2004). Prevalence of violence against dating partners by male and female university students worldwide. Violence Against Women, 10(7), 790.

Straus, M. A., \& Savage, S. A. (2005). Neglectful behavior by parents in the life history of university students in 17 countries and its relation to violence against dating partners. Child Maltreatment, 10(2), 124. 
Taussig, H. N. (2002). Risk behaviors in maltreated youth placed in foster care: A longitudinal study of protective and vulnerability factors. Child Abuse and Neglect, 26(11), 1179-1200.

Toth, S. L., Maughan, A., Manly, J. T., Spagnola, M., \& Cicchetti, D. (2002). The relative efficacy of two interventions in altering maltreated preschool children's representational models: Implications for attachment theory. Development and Psychopathology, 14(4), 877-908.

van IJzendoorn, M. H., Goldberg, S., Kroonenberg, P. M., \& Frenkel, O. J. (1992). The relative effects of maternal and child problems on the quality of attachment: A meta-analysis of attachment in clinical samples. Child Development, 63, 840-858.

van IJzendoorn, M. H., Schuengel, C., \& Bakermans-Kranenburg, M. J. (1999). Disorganized attachment in early childhood: Meta-analysis of precursors, concomitants, and sequelae. Development and Psychopathology, 11, 225-249.

Vezina, J., \& Hebert, M. (2007). Risk factors for victimization in romantic relationships of young women. Trauma, Violence, \& Abuse, 8(1), 33.

Vig, S., \& Kaminer, R. (2002). Maltreatment and developmental disabilities in children. Journal of Developmental and Physical Disabilities, 14(4), 371-386.

Waechter, R. L., Wekerle, C., Leslie, B., Goodman, D., Wathen, C. N., Moddy, B., \& MAP Team (2009). Child protection services and university-based partnerships: a participatory action-based model for sharing knowledge. First Peoples Child and Family Review, 4(2), 118-128.

Wall, A., \& McKee, S. (2002). Cognitive social learning models of substance use and 
intimate violence. In C. Wekerle \& A. Wall (Eds.), The violence and addiction equation: Theoretical and clinical issues in substance abuse and relationship violence (pp. 123-149). New York, NY: Brunner-Routledge.

Ward, K. M., Bosek, R. L., \& Trimble, E. L. (2010). Romantic relationships and interpersonal violence among adults with developmental disabilities. Intellectual and Developmental Disabilities, 48, 89-98.

Weiss, J. A., Waechter, R., Wekerle, C., \& the MAP Research Team. (in press). The impact of emotional abuse on psychological distress among child protective services-involved adolescents with borderline-to-mild intellectual disability. Journal of Child and Adolescent Trauma.

Wekerle, C., \& Avgoustis, E. (2003). Child maltreatment, adolescent dating, and adolescent dating violence. In P. Florsheim (Ed.), Adolescent romantic relations and sexual behavior: Theory, research and practical implications (pp. 213-241). Hillsdale, NJ: Erlbaum.

Wekerle, C., Leung, E., Wall, A. M., MacMillan, H., Boyle, M., Trocme, N., \& Waechter, R. (2009). The contribution of childhood emotional abuse to teen dating violence among child protective services-involved youth. Child Abuse \& Neglect, 33(1), 45-58.

Wekerle, C., \& Wolfe, D. A. (1998). The role of child maltreatment and attachment style in adolescent relationship violence. Development and Psychopathology, 10(3), $571-586$.

Wekerle, C., Wolfe, D. A., Hawkins, D. L., Pittman, A. L., Glickman, A., \& Lovald, B. E. (2001). Childhood maltreatment, posttraumatic stress symptomatology, and 
adolescent dating violence: Considering the value of adolescent perceptions of abuse and a trauma mediational model. Development and Psychopathology, 13(4), $847-871$.

Willemsen-Swinkels, S. H. N., Bakermans-Kranenburg, M. J., Buitelaar, J. K., van IJzendoorn, M. H., \& van Engeland, H. (2000). Insecure and disorganized attachment in children with a pervasive developmental disorder: Relationship with social interaction and heart rate. Journal of Child Psychology and Psychiatry, 41(6), 759-767.

Wolfe, D. A., Crooks, C. C., Chiodo, D., \& Jaffe, P. (2009). Child Maltreatment, bullying, gender-based harassment, and adolescent dating violence: Making the connections. Psychology of Women Quarterly, 33(1), 21-24.

Wolfe, D. A., Scott, K., Wekerle, C., Grasley, C., \& Straatman, A. L. (2001). Development and validation of the conflict in adolescent dating relationships inventory. Psychological Assessment, 13, 277-293.

Wolfe, D. A., Wekerle, C., \& Gough, R., Reitzel-Jaffe, D. Grasley, C., Pittman, A., et al. (1996). The youth relationships manual: A group approach with adolescents for the prevention of woman abuse and the promotion of healthy relationships. Sage Publications, Inc.

Wolfe, D. A., Wekerle, C., Scott, K., Straatman, A. L., \& Grasley, C. (2004). Predicting abuse in adolescent dating relationships over 1 year: The role of child maltreatment and trauma. Journal of Abnormal Psychology, 113(3), 406-415.

Wolfe, D. A., Wekerle, C., Scott, K., Straatman, A., Grasley, C., \& Reitzel-Jaffe, D. (2003). Dating violence prevention with at-risk youth: A controlled outcome 
Maltreatment in Intellectual Disability 50

evaluation. Journal of Consulting \& Clinical Psychology, 71(2), 279-291. 